\title{
Calcium adsorption and displacement: characterization of lipid monolayers and their interaction with membrane-active peptides/proteins
}

\author{
Sven O Hagge, Malte U Hammer, Andre Wiese, Ulrich Seydel and \\ Thomas Gutsmann*
}

Address: Research Center Borstel, Leibniz-Center for Medicine and Biosciences, Department of Immunochemistry and Biochemical Microbiology, Division of Biophysics, Parkallee1-40, D-23845 Borstel, Germany

Email: Sven O Hagge - shagge@fz-borstel.de; Malte U Hammer - mhammer@fz-borstel.de; Andre Wiese - awiese@gmx.net;

Ulrich Seydel - useydel@fz-borstel.de; Thomas Gutsmann* - tguts@fz-borstel.de

* Corresponding author

Published: 03 May 2006

BMC Biochemistry 2006, 7:15 doi:10.1186/1471-2091-7-15

This article is available from: http://www.biomedcentral.com//47/-209//7//5

(c) 2006 Hagge et al; licensee BioMed Central Ltd.

This is an Open Access article distributed under the terms of the Creative Commons Attribution License (http://creativecommons.org/licenses/by/2.0), which permits unrestricted use, distribution, and reproduction in any medium, provided the original work is properly cited.

\begin{abstract}
Background: The first target of antimicrobial peptides (AMPs) is the bacterial membrane. In the case of Gram-negative bacteria this is the outer membrane (OM), the lipid composition of which is extremely asymmetric: Whereas the inner leaflet is composed of a phospholipid mixture, the outer leaflet is made up solely from lipopolysaccharides (LPSs). LPS, therefore, represents the first target of AMPs. The binding and intercalation of polycationic AMPs is driven by the number and position of negatively charged groups of the LPS. Also, proteins other than cationic AMPs can interact with LPS, e.g. leading eventually to a neutralization of the endotoxic effects of LPS. We compared different biophysical techniques to gain insight into the properties of the electrical surface potentials of lipid monolayers and aggregates composed of LPSs and various phospholipids and their interaction with peptides and proteins.

Results: The net negative charge calculated from the chemical structure of the phospholipid and LPS molecules is linearly correlated with the adsorption of calcium to two-dimensional lipid monolayers composed of the respective lipids. However, the $\zeta$-potentials determined by the electrophoretic mobility of LPS aggregates can only be interpreted by assuming a dependence of the plane of shear on the number of saccharides and charged groups. Various peptides and proteins were able to displace calcium adsorbed to monolayers.

Conclusion: To characterize the electrical properties of negatively charged phospholipids and LPSs and their electrostatic interaction with various polycationic peptides/proteins, the adsorption of calcium to and displacement from lipid monolayers is a suitable parameter. Using the calcium displacement method, the binding of peptides to monolayers can be determined even if they do not intercalate. The interpretation of $\zeta$-potential data is difficulty for LPS aggregates, because of the complex three-dimensional structure of the LPS molecules. However, the influence of peptides/ proteins on the $\zeta$-potential can be used to characterize the underlying interaction mechanisms.
\end{abstract}


A
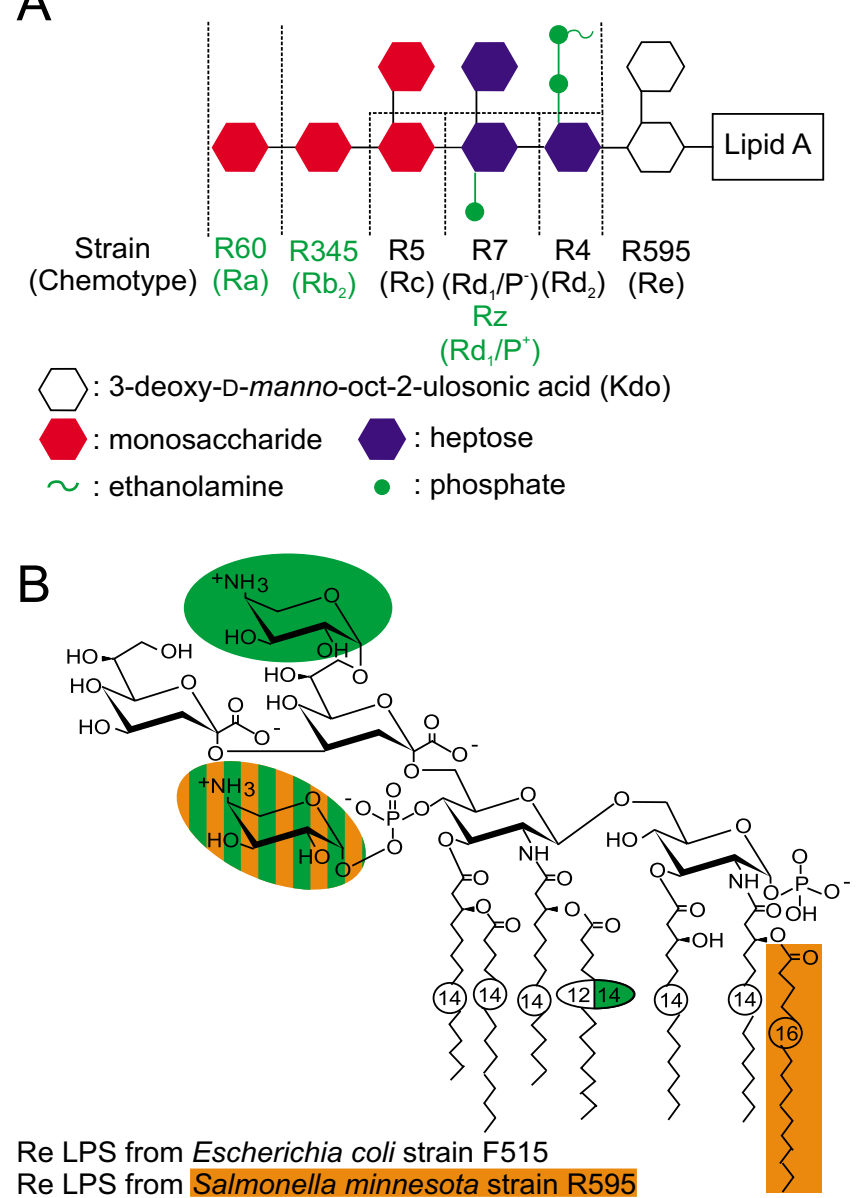

Re LPS from Salmonella minnesota strain R595

Re LPS from Proteus mirabilis strain R45

Figure I

Chemical structures of the LPSs used. (A) Schematic chemical structure of the core region of LPSs from different rough mutant strains of Salmonella minnesota and its chemotypes ( $R a$ to $R e$ ). The phosphate residue at the second heptose and the 2-aminoethyl diphosphate residue at the first heptose are only present in the mutants Rz, R345 and R60.

(B) Chemical structure of Re LPSs from various Gram-negative species, i.e., Escherichia coli strain F5I5, Salmonella minnesota strain R595, and Proteus mirabilis strain R45.

\section{Background}

Cell membranes composed of lipids and proteins are an essential part of all living organisms. The interaction between peptides or proteins and lipid membranes is driven by entropic effects and in many cases also by electrostatic forces. The architecture of membranes differs for various cell types and with that also the specificity of the interaction between lipids and peptides/proteins.

The cytoplasmic membrane of mammalian cells has an asymmetric lipid distribution [1], in particular phosphatidylserine (PS) is almost exclusively located in the inner leaflet of the membrane, and in the early steps of apoptotic cell death it is translocated into the outer leaflet [2]. It has been shown that an increased amount of PS in the outer leaflet, e.g. in cancer cells, can lead to increased binding of the polycationic NK-lysine derived peptide NK-2 and a preferential killing of these cells [3].

The important influence of electrostatic interactions is even more pronounced for the interaction between bacteria and antimicrobial peptides (AMPs) of the innate host defense system. Membranes of Gram-positive as well as of Gram-negative bacteria express a high amount of negatively charged lipids on the outer leaflet of the membrane which is in direct contact with the extracellular environment.

Gram-positive bacteria have a cytoplasmic membrane containing negatively charged diphosphatidylglycerol (DPG, cardiolipin) [4] and lipoteichoic acid (LTA) [5] on the outer leaflet. The cell envelope of Gram-negative bacteria is composed of two membranes, the inner and the outer membrane. The inner leaflet of the outer membrane is composed of phospholipids and the outer leaflet of glycolipids, in most cases lipopolysaccharides (LPSs, endotoxin) [6]. LPS is negatively charged due to phosphate groups linked to the di-glucosamin sugar backbone and to the 3-deoxy-alpha-D-manno-oct-2-ulosonic acids (Kdo's) and further negatively charged residues (Fig. 1). This highly negatively charged surface is the first target for a number of polycationic AMPs, e.g. defensins [7], cathelicidins [8], bactericidal/permeability increasing protein (BPI) [9], and magainins [10]. Many AMPs and other polycationic peptides have a dual function, they are antimicrobial and they can reduce or even inhibit the LPSinduced activation of human mononuclear cells. A reduction of the LPS-induced cytokine release has been shown for the endotoxin-neutralizing protein (ENP) [11], polymyxin B [12], lysozyme [13], peptides based on Limulus anti-lipopolysacchride factor [14], and a number of further peptides and proteins. Moreover, the charges of LPS are important for the interaction between LPS and proteins which are involved in the LPS-induced transmembrane signal transduction, e.g. the LPS-binding protein [15], leading to the release of cytokines (for review see [16]).

To investigate the interactions between negatively charged lipids and polycationic peptides/proteins on a molecular level, the knowledge of the number of charges per lipid molecule or the surface charge density of the lipid aggregates is of importance. A number of techniques to determine these parameters is available. Some of the methods can be applied for whole cells or bacteria (for review see [17]), for lipid aggregates, for planar lipid bilayers, or for lipid monolayers. 


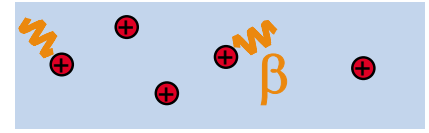

1. ${ }^{45} \mathrm{Ca}^{2+}$ containing subphase

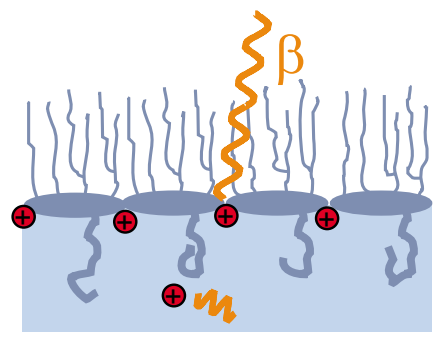

2. Preparation of monolayer

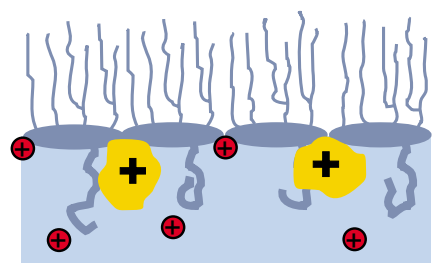

3. Addition of peptide

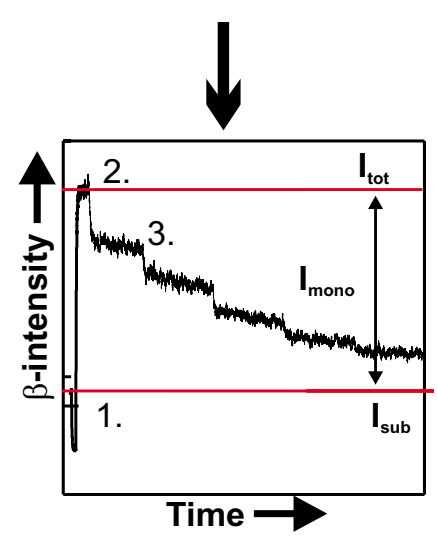

Figure 2

The calcium displacement technique. The $\beta$-radiation emitted from ${ }^{45} \mathrm{Ca}^{2+}$ ions in an aqueous subphase is shielded by the aqueous layer above the ions, yielding the $\beta$-intensity $I_{\text {sub }}$. (2.) A monolayer prepared on the subphase leads to the adsorption of calcium and in particular of ${ }^{45} \mathrm{Ca}^{2+}$ ions to the surface, and subsequently a higher $\beta$-radiation $I_{\text {tot }}$ can be detected. The $\beta$-intensity resulting from the monolayer can be calculated as $I_{\text {mono }}=I_{\text {tot }}-I_{\text {sub }}$. (3.) Substances having a higher affinity to the lipid monolayer as compared to $\mathrm{Ca}^{2+}$ lead to the displacement of the $\mathrm{Ca}^{2+}$ ions from the surface and a reduction of the $\beta$-intensity $I_{\text {tor }}$. The titration of peptides/proteins into the buffer can lead to a time trace of the $\beta$-intensity as depicted exemplarily in the lower trace.
Four different methods to determine values which depend on the number of charges per molecule and the size of the molecules are compared in this paper for phospholipids and, in particular, for LPS:

(i) Calculation of the net charge per molecule which is based on the chemical structure as determined in mass spectrometric experiments.

(ii) Determination of innermembrane potentials of monolayers $[18,19]$ or planar lipid bilayers $[20,21]$.

(iii) Determination of the electrophoretic mobility of cells and lipid aggregates. From the electrophoretic mobility, the $\zeta$-potential can be calculated which is correlated with the surface charge density [17].

(iv) Utilization of marker molecules, which bind to specific lipids, e.g. annexin $\mathrm{V}$ as a marker for PS in apoptotic cells, or to charged residues, e.g. calcium doped with small amounts of the $\beta$-active isotope ${ }^{45} \mathrm{Ca}^{2+}$ as a marker for negatively charged lipids.

The special focus is directed on the determination of the relative number of charges per molecule by measuring the amount of calcium adsorbed to lipid monolayers by monitoring low-energy $\beta$-radiation of ${ }^{45} \mathrm{Ca}^{2+}$. The measurement of the adsorption of calcium to monolayers and also its displacement (Fig. 2) induced by the adsorption of various polycationic peptides and proteins is a technique which has been proven useful for studying the binding of pharmaceuticals to lipid monolayers [22-25].

In this paper, we used the adsorption of calcium to and displacement from lipid monolayers to characterize phospholipids and LPS monolayers and their interaction with a number of peptides/proteins. The results are compared with those obtained from calculations of the net negative charges on the basis of the chemical structure of the respective lipids, $\zeta$-potential measurements and already published results obtained from innermembrane potential difference measurements using planar lipid bilayers [26]. The calculated number of charges per lipid molecule is linearly correlated with the adsorption of calcium.

\section{Results \& discussion}

\section{Determination of surface potentials of lipid aggregates}

Charged residues in the headgroup of lipid molecules as well as attracted counter ions cause an electrical potential at the surface of the respective aggregates, the so-called Gouy-Chapman potential which decreases exponentially in the surrounding buffer (for review see [27]). Due to friction forces, aggregates moving in an externally applied electric field will loose weakly bound ions. The GouyChapman potential at the interface between weakly and 
Table I: Properties of lipopolysaccharides and phospholipids used in this study. Given are the biochemical specifications of all lipids used in this study, the net charge calculated from mass spectrometric data, the results obtained from calcium adsorption experiments, given as the maximum $\beta$-intensity $I_{\max }$ calculated according to Eq. 3, the electrophoretic mobilities $\mu$, and the $\zeta$-potential values. (n.d. - not determined, * - the values for phosphatidylcholine and phosphatidylglycerol could only be estimated)

\begin{tabular}{|c|c|c|c|c|c|c|}
\hline \multicolumn{7}{|c|}{ Lipopolysaccharid } \\
\hline Species & Strain & LPS chemotype & $\begin{array}{l}\text { calculated net } \\
\text { charge/ } / e_{0}\end{array}$ & $I_{\max } / \mathrm{cps}$ & $\mu / 10^{-8} \mathrm{~m}^{2} \mathrm{~V}^{-1} \mathbf{s}^{-1}$ & $\zeta$-potential $/ \mathrm{mV}$ \\
\hline \multirow[t]{7}{*}{ S. minnesota } & R595 & $\operatorname{Re}$ & -3.6 & $265.8 \pm 65.3$ & $-2.13 \pm 0.13$ & $-27.2 \pm 1.7$ \\
\hline & R4 & $\mathrm{Rd}_{2}$ & -4.0 & $345.3 \pm 85.2$ & $-3.90 \pm 0,63$ & $-49.9 \pm 8.1$ \\
\hline & R7 & $\mathrm{Rd}_{1}$ & -4.1 & $307.9 \pm 41.3$ & $-4.35 \pm 0.06$ & $-55.7 \pm 0.8$ \\
\hline & $\mathrm{Rz}$ & $\mathrm{Rd}_{1}$ & -5.3 & $537.6 \pm 69.2$ & $-3.09 \pm 0.28$ & $-39.5 \pm 3.6$ \\
\hline & R5 & $\mathrm{Rc}$ & -4.1 & $307.9 \pm 37.8$ & $-2.65 \pm 0.45$ & $-33.9 \pm 5.7$ \\
\hline & R345 & $\mathrm{Rb}_{2}$ & -4.8 & $545.9 \pm 105.0$ & $-|.04 \pm 0.4|$ & $-13.3 \pm 5.2$ \\
\hline & $\mathrm{R} 60$ & $\mathrm{Ra}^{2}$ & -6.0 & $480.8 \pm 91.6$ & $-2.63 \pm 0.03$ & $-33.7 \pm 0.4$ \\
\hline E. coli & F5I5 & $\operatorname{Re}$ & -4.0 & $451.6 \pm 119.7$ & $-3.27 \pm 0.12$ & $-41.9 \pm 1.5$ \\
\hline P. mirabilis & R45 & $\operatorname{Re}$ & -3.0 & $265.8 \pm 65.3$ & $-4.21 \pm 0.09$ & $-53.9 \pm 1.2$ \\
\hline \multicolumn{7}{|c|}{ Phospholipids } \\
\hline & & & $\begin{array}{l}\text { calculated net } \\
\text { charge } / e_{0}\end{array}$ & $I_{\max } / \mathrm{cps}$ & $\mu / 10^{-8} \mathbf{m}^{2} V^{-1} \mathbf{s}^{-1}$ & $\zeta$-potential/mV \\
\hline \multicolumn{3}{|c|}{ phosphatidylglycerol } & -1.0 & $\sim 60 \pm 44.4^{*}$ & $-5.76 \pm 0.23$ & $-73.7 \pm 2.9$ \\
\hline \multicolumn{3}{|c|}{ phosphatidylserine } & -1.0 & n.d. & $-5.09 \pm 1.37$ & $-65.1 \pm 17.5$ \\
\hline \multicolumn{3}{|c|}{ diphosphatidylglycerol } & -2.0 & $182.4 \pm 61.8$ & $-5.83 \pm 0.66$ & $-74.6 \pm 8.4$ \\
\hline \multicolumn{3}{|c|}{ phosphatidylcholine } & 0 & $\sim 0 \pm 23.4^{*}$ & $-0.43 \pm 0.10$ & $-5.5 \pm 1.3$ \\
\hline \multicolumn{3}{|c|}{ phosphatidylethanolamine } & 0 & n.d. & $-1.20 \pm 0.03$ & $-15.4 \pm 0.4$ \\
\hline
\end{tabular}

strongly bound ions, the plane of sheer, is called $\zeta$-potential. From the velocity of the aggregates in an electric field, the electrophoretic mobility, the $\zeta$-potential can be calculated via the Smoluchowski approximation [28].

To investigate the influence of lipid structures, in particular the presence of negatively charged groups, on the surface potential, we determined the electrophoretic mobility and calculated the respective $\zeta$-potentials of various aggregates made from LPSs or phospholipids. The respective values are given in Tab. 1 . In Fig. 3 , the $\zeta$-potential values for all lipids are plotted versus their net negative charges (calculated from the structure shown in Fig. 1, i.e., the amount of phosphate groups, Kdo's, 4-amino-4deoxyarabinose (Ara4N), etc.) of the respective lipids.

In the case of phospholipids, the absolute values of the $\zeta$ potential increase linearly with increasing negative net surface charge as it could be proposed form the $\zeta$-potential theory. The $\zeta$-potential and the surface charge density of PG and DPG is almost the same, because the net charge as well as the surface area occupied by a DPG molecule is twice of that of a PG molecule. For the various LPSs used, we did not find any correlation between the calculated net charge and the $\zeta$-potential. This might be explained by incorrect assumptions for the calculation of the $\zeta$-potentials from the electrophoretic mobility. The determination of the $\zeta$-potential is based on the Smoluchowski approximation [28] assuming a homogenously charged, smooth surface. In comparison to phospholipids, LPS molecules have relatively large headgroups with an oligosaccharide extending into the surrounding buffer. In addition, positively (Ara4N) and negatively charged groups (phosphate groups and Kdo's) are heterogeneously distributed in the lipid A part and the oligosaccharide.

Phospholipids are described to form multilamellar vesicles. Aggregates formed by LPS are also described to be multilamellar in the presence of di- or polyvalent ions at a temperature of $25^{\circ} \mathrm{C}[29,30]$. It can be assumed that phospholipids and LPS vesicles are completely enclosed by bilayers under the conditions used in this study and, thus, the electrostatic properties of the outer leaflet of these vesicles are probably comparable with those of monolayers.

The surface potential profiles of LPS aggregates can be calculated according to the Gouy-Chapman theory [27] using the respective net charges (Tab. 1) and areas per LPS molecules which can be calculated from the amount of fatty acids (Tab. 2) [29]. The calculated values of the molecular areas have also been verified by determining the areas from pressure/area isotherms of monolayers. As shown by Pasquale et al [31], the planes of shear can be 


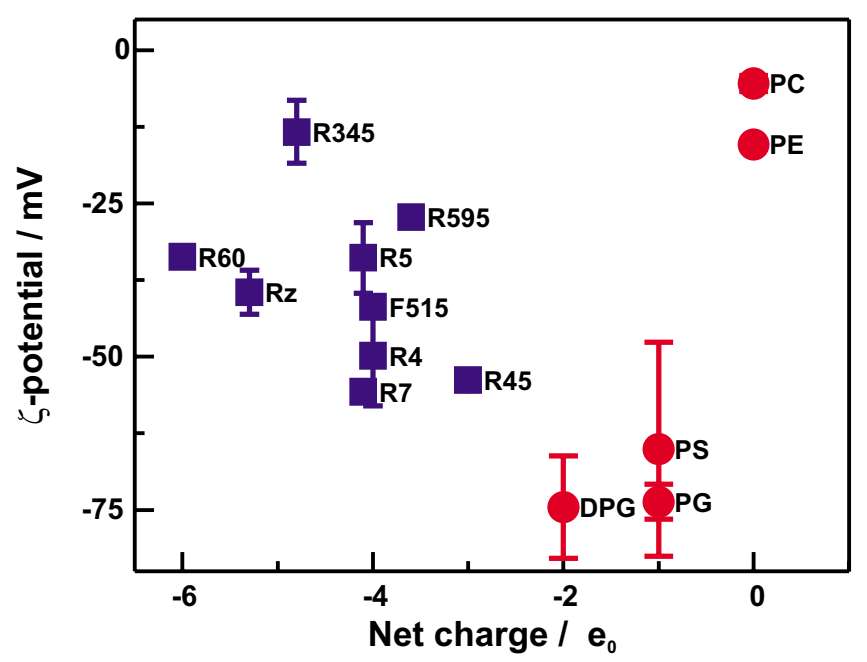

Figure 3

Surface potential of lipid aggregates. The $\zeta$-potentials of aggregates made of LPS $(\square)$ or phospholipids $(O)$ are plotted versus the net charge of the respective lipid molecules. $\zeta$-potentials were measured in buffer containing 10 $\mathrm{mM}$ Tris, $2 \mathrm{mM} \mathrm{CsCl}$ and $\mathrm{pH}$. The lipid concentration was $0.01 \mathrm{mM}$. The net charges were calculated from the chemical structures determined by mass spectrometry.

calculated from measured $\zeta$-potentials and calculated surface potentials. The distances $d_{1}$ between the aggregate surfaces and the planes of shear are in the range between $0.20 \mathrm{~nm}$ (LPS R7) and $0.42 \mathrm{~nm}$ (LPS R60) (Tab. 2). These calculated distances do not correlate with structural data, i.e. net charge and number of core sugars of the respective LPS, due to the fact that the model assumes smooth surfaces with homogeneous charge distributions.

Snyder et al. [29] concluded from electron density profiles of LPS R60 that its charges are located mainly in two distinct planes which are separated by a distance of $1.1 \mathrm{~nm}$. The outer charged plane corresponds to the negatively charged phosphate groups linked to the heptoses in the core region of the LPS, the inner charged plane to the phosphate groups of the lipid A moiety. Using this model, we calculated the surface potential profiles of aggregates composed of those LPS having heptoses substituted with significant numbers of phosphate groups (LPS Rz, LPS R345, LPS R60) as superpositions of the Gouy-Chapman potential profiles $\Psi_{\mathrm{I}}$ and $\Psi_{\mathrm{O}}$ for the inner and the outer plane, respectively:

(Eq.1) $\Psi_{\mathrm{GC}}(x)=\Psi_{\mathrm{I}} \exp (-\kappa x)+\Psi_{\mathrm{O}} \exp (-\kappa(x-1.1 \mathrm{~nm}))$ for $x \geq 1.1 \mathrm{~nm}$ where $x$ is the distance from the inner charged plane and $\kappa$ is the reciprocal Debye- length [27].

$\Psi_{\mathrm{GC}}$ at the plane of shear corresponds to the $\zeta$-potential. Using Eq. 1, the distance of the plane of shear $d_{2}$ can be calculated according to:

(Eq. 2) $d_{2}=-\ln \left(\zeta /\left[\Psi_{\mathrm{I}}+\Psi_{\mathrm{O}} \exp (\kappa 1.1 \mathrm{~nm})\right]\right) / \kappa$.

The respective values for the $S$. minnesota LPS used in this study are given in Tab. 2 . These results indicate that additional charges have a greater influence on the position of the plane of shear than an increased hydrodynamic drag resulting from additional saccharide groups. Studies on the influence of saccharides and charges of ganglioside $\mathrm{G}_{\mathrm{M} 1}[31,32]$ and PEG-PE [33] showed that the enhanced hydrodynamic drag of additional saccharides has a higher influence on the electrophoretic mobility of the respective particles than the amount and/or position of additional charges.

It should, however, be pointed out that our approach to describe the surface potential by the superposition of two distinct planes is only a simplified model. For example, the charges of the two phosphate groups of the lipid A and the two Kdo were assumed to be in one plane, however, the diglucosamine backbone of the lipid A moiety of the LPS is tilted with respect to the aggregate surface [34]. Thus, the charges are rather distributed in a volume than in a distinct plane.

Several advanced theories, taking a rough surface of the aggregate into account, have been published (for review see [35]). However, it should be mentioned that it is necessary to have detailed information on the 3D structures of the involved molecules. In case of a natural oligosaccharide, a defined 3D structure in solution has not been published so far, and because of a potential flexibility of oligosaccharides it is unlikely that structures can be determined which are precise enough for an accurate model to calculate surface potential profiles.

\section{Calcium adsorption to lipid monolayers}

To investigate the adsorption of calcium to lipid monolayers made of various phospholipids and LPSs, calcium (doped with radioactive ${ }^{45} \mathrm{Ca}^{2+}$ ) was titrated in amounts of up to $25 \mu \mathrm{M}$ into the subphase underneath the monolayers composed of the identical number of the respective lipid molecules. The $\beta$-intensity was measured and plotted against the calcium concentration. To further analyze the data, the plots were fitted by the equation:

(Eq. 3) $I(c)=I_{\max }\left(1-\exp \left(-\frac{c}{c_{0}}\right)\right)$ 
Table 2: Calculated surface charge densities and planes of shear of the $S$. Minnesota LPS. The areas per molecule $A$ were calculated according to Snyder et al [29], using the respective amounts of fatty acids determined from mass spectrometric data. The charge densities $\sigma$ were calculated from $A$ and the net negative charges given in Tab. I. $d_{1}$ and $d_{2}$ represent the distances of the planes of shear from the aggregate surface taking into account I or $\mathbf{2}$ charged planes, respectively.

\begin{tabular}{lcccc}
\hline Strain & $\mathbf{A} / \mathbf{n m}^{\mathbf{2}}$ & $\sigma / \mathbf{e}_{\mathbf{0}} \mathbf{n m}^{-\mathbf{2}}$ & $\mathbf{d}_{\mathbf{1}} / \mathbf{n m}$ & $\mathbf{d}_{\mathbf{2}} / \mathbf{n m}$ \\
\hline LPS R595 & 1.18 & 3.04 & 0.40 & - \\
LPS R4 & 1.29 & 3.11 & 0.23 & - \\
LPS R7 & 1.26 & 3.26 & 0.20 & - \\
LPS Rz & 1.05 & 5.04 & 0.36 & - \\
LPS R5 & 1.26 & 3.26 & 0.35 & 1.26 \\
LPS R345 & 1.19 & 4.02 & 0.24 & 1.04 \\
LPS R60 & 1.04 & 5.75 & 0.42 & 1.38 \\
\hline
\end{tabular}

where $I(c)$ is the $\beta$-intensity $I$ as a function of the calcium concentration $c, I_{\max }$ the maximum $\beta$-intensity at complete saturation of the lipid monolayer with calcium and $c_{0}$ is the calcium concentration at which 1-1/e ( 63\%) of the monolayer is saturated with calcium. In Fig. 4, respective titration curves are shown exemplarily for DPG (red), LPS R45 (green), and LPS R60 (blue).

In Fig. 5, $I_{\max }$ is plotted versus the net charge $q$ of all lipids used for monolayer preparation. The respective values are given in Tab. 1 . We found, that $I_{\max }$ increases with increasing negative values of $q$ and that $I_{\max }$ and $q$ are linear correlated with $\mathrm{R}=-0.98$. The dependence of $I_{\max }$ on $q$ is given by $I_{\max }=(-3.1 \pm 21.0) \mathrm{cps}+(-89.3 \pm 6.5) \mathrm{cps} / \mathrm{e}_{0} q$.

These results indicate that the amount of calcium adsorbed to a lipid monolayer depends solely on the number of negative charges and is not influenced by the $3 \mathrm{D}$ structure of the monolayer-forming lipid. Furthermore, it can be assumed from the linear correlation between $q$ and $I_{\max }$ that calcium ions intercalate into the oligosaccharide portion of the LPS, also binding directly to the charged groups of the lipid A part of the molecule. This is supported by calcium displacement experiments using fragments of rabbit and human cathelicidin peptide [36], in which some fragments were not able to displace $100 \%$ of the calcium adsorbed to the monolayer, indicating that some of the calcium ions are not accessible for the peptide.

\section{Influence of the lateral pressure on calcium adsorption}

To check the influence of the lateral pressure on calcium adsorption, we used a Langmuir-Pockels film balance equipped with a movable barrier. LPS F515 monolayers were prepared and compressed to a final lateral pressure of $40 \mathrm{mN} \mathrm{m}^{-1}$, and the $\beta$-intensity was monitored.

In Fig. 6A, one representative pressure/area isotherm is shown. Up to $\sim 20 \mathrm{mN} \mathrm{m}^{-1}$, the lateral pressure increases almost linearly with decreasing area, above $20 \mathrm{mN} \mathrm{m}^{-1}$ the isotherm shows a typical non-linear dependence between area and lateral pressure. In contrast to the latter, the $\beta$ intensity increases linearly with decreasing film area (Fig. $6 \mathrm{~B})$. The increase of the $\beta$-intensity is due to the increased number of lipid molecules per unit of area and with that also below the detector. Thus, the amount of adsorbed calcium per molecule does not depend on the area per molecule or the lateral pressure in the monolayer, but solely on the number of molecular charge per unit of area.

\section{Calcium displacement by peptides/proteins}

To investigate the binding of various antimicrobial and LPS-neutralizing substances (Tab. 3) to lipid monolayers made from LPS, we performed calcium displacement experiments. Injections of increasing amounts of the peptides/proteins underneath the calcium saturated monolayers led to a decrease in the $\beta$-intensities due to a displacement of the calcium ions by the peptides/proteins. In Fig. 7, respective titration curves are given exemplarily for the nonapeptide of polymyxin $\mathrm{B}(\mathrm{PMBN})$ and lysozyme. The peptide PMBN led already at low micromolar concentrations to a strong decrease in $\beta$-intensity to almost the bulk level $I_{\text {sub }}$, indicating a full displacement of

Table 3: $I C_{50}$ calcium displacement values for various peptides/ proteins. The molecular weights and the $\mathrm{IC}_{50}$-values (concentration of the peptides/proteins necessary to displace $\mathbf{5 0 \%}$ of the calcium adsorbed to LPSF5 I 5 monolayers) are shown. Bathing solution: I $2.5 \mu \mathrm{M}$ calcium doped with radioactive ${ }^{45} \mathrm{Ca}^{2+}$ resulting in a relative $\beta$-activity of $250 \mathrm{~Bq} / \mathrm{ml}$, buffered with $5 \mathrm{mM}$ HEPES, and adjusted to pH7; the LPSF5 I 5 concentration was 9.6 $\mathrm{nmol}(160 \mathrm{nM})$.

\begin{tabular}{lll}
\hline Peptide/Protein & MW & IC $_{50} / \mu \mathbf{M}$ \\
\hline rCAPI8 & 3801 & 0.22 \\
lactoferrin & 78922 & 0.12 \\
rBPI2I & 21063 & 0.16 \\
PMB & 1200 & 0.84 \\
PMBN & 963 & 0.76 \\
lactalbumin & 66000 & 1 \\
lysozyme & 14400 & 6.9 \\
rHSA & 66000 & 14 \\
hemoglobin & 64000 & 32 \\
\hline
\end{tabular}




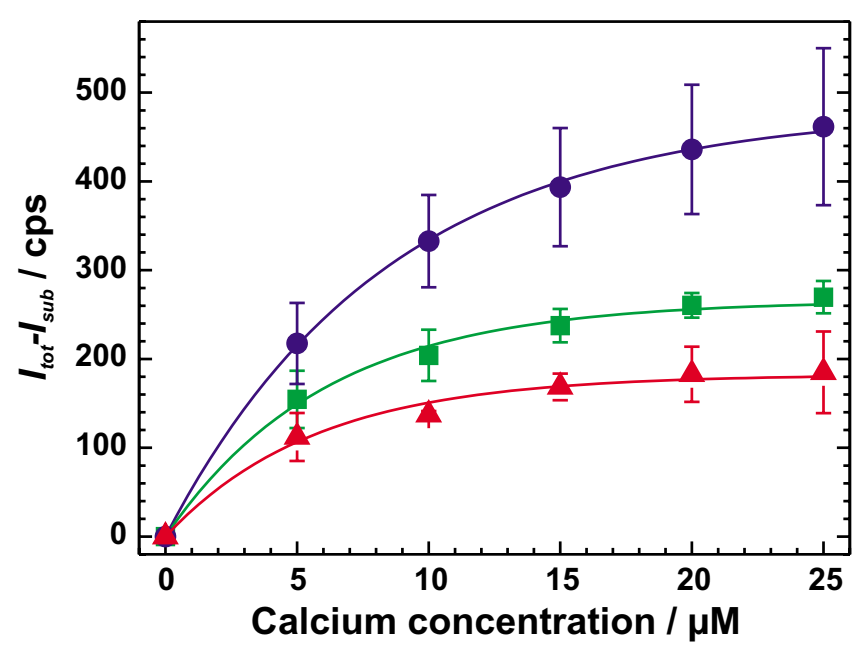

Figure 4

Titration of calcium into the subphase underneath various monolayers. Calcium was titrated into the subphase underneath various monolayers. The results are shown exemplarily for DPG ( $\left.{ }^{\Delta}\right)$, LPS R45 ( $\left.{ }^{\square}\right)$, and LPS $\mathrm{R} 60$ (O). The data points represent the mean intensities determined from 3 independent experiments. The lines represent fits of the respective titration curves applying Eq. 3 . Calcium adsorption was measured in a buffer solution containing $5 \mathrm{mM}$ HEPES at $\mathrm{pH}$. The net charges were calculated from mass spectrometric data.

calcium from the monolayer. In the case of lysozyme, the ability to displace calcium from the monolayer was significantly lower.

To compare the various peptides/proteins in their ability to displace calcium from an LPS monolayer, the $\mathrm{IC}_{50}$ values (the peptide concentration at which the $\beta$-intensity decreases to $50 \%$ of the saturation value) were calculated. The most potent substances were the proteins lactoferrin and the bactericidal/permeability-increasing protein (rBPI21) and a fragment of the $18 \mathrm{kDa}$ rabbit cationic antimicrobial protein (rCAP18 ${ }_{106-137}$ ) which were active already at submicromolar concentrations. The $\mathrm{IC}_{50}$ values of the recombinant human serum albumin (rHSA) and hemoglobin were by two orders of magnitude higher. Interestingly, rCAP18, PMB, BPI, and lactoferrin are wellknown LPS-neutralizing peptides [37]. In contrast to this, rHSA and hemoglobin do not inhibit the LPS-induced activation of human mononuclear cells [38], in case of hemoglobin the TNF $\alpha$ production is even increased [39]. Thus, the ability of the peptides/proteins to displace calcium from LPS monolayers seems to be correlated with their ability to neutralize LPS.

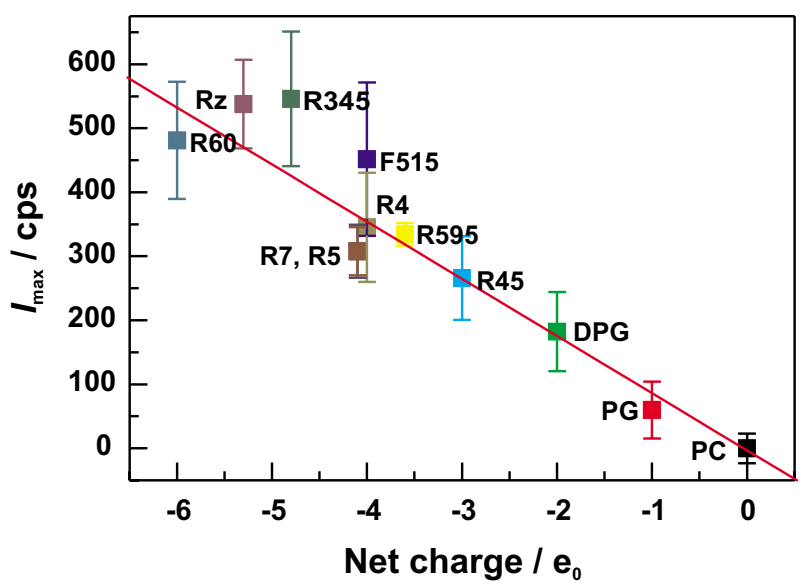

Figure 5

Calcium adsorption to lipid monolayers. The saturation values of calcium adsorption traces of lipid monolayers made of LPS or phospholipids are plotted versus the net charge of the respective lipid molecules. Calcium adsorption was measured in a buffer solution containing $5 \mathrm{mM}$ HEPES at $\mathrm{pH} 7$. The net charges were calculated from mass spectrometric data.

Divalent cations lead to a cross linking between the LPS individual molecules [40] and lead, therefore, to an increased binding energy within the aggregate surface. Probably, the polyvalent peptides/proteins lead to a binding energy, which is higher than that provoked by divalent cations such as $\mathrm{Mg}^{2+}$ or $\mathrm{Ca}^{2+}$. Thus, the binding of LPS to proteins being involved in the LPS-induced activation of mononuclear cells is inhibited.

In many cases, the intercalation of peptides/proteins decreases with increasing lateral pressure. Therefore, to guarantee a maximal interaction between the monolayers and the peptides/proteins, experiments were done at a relatively low lateral pressure as compared to that in a natural cell membrane which is discussed to be in the range from 20 to $30 \mathrm{mN} \mathrm{m}^{-1}[41,42]$.

In the next step of our experiments we investigated the ability of PMB to bind to LPS monolayers without intercalating into it at high lateral pressures. When $500 \mu \mathrm{l}$ of a $350 \mu \mathrm{M}$ PMB solution were injected into the subphase $(250 \mathrm{ml})$ underneath an LPSF515 monolayer at a constant lateral pressure of $27 \mathrm{mN} \mathrm{m}^{-1}$, no significant change of the film area was observed (Fig. 8A), indicating that PMB does not intercalate into the lipid matrix at this lateral pressure. However, it led to a decrease in $\beta$-intensity of about $10 \%$ within 60 min after peptide addition (Fig. 8B), demonstrating that $\mathrm{PMB}$, even if it is not able to intercalate into the monolayer and increase its surface area, it is able to bind to the monolayer surface and to displace calcium. 


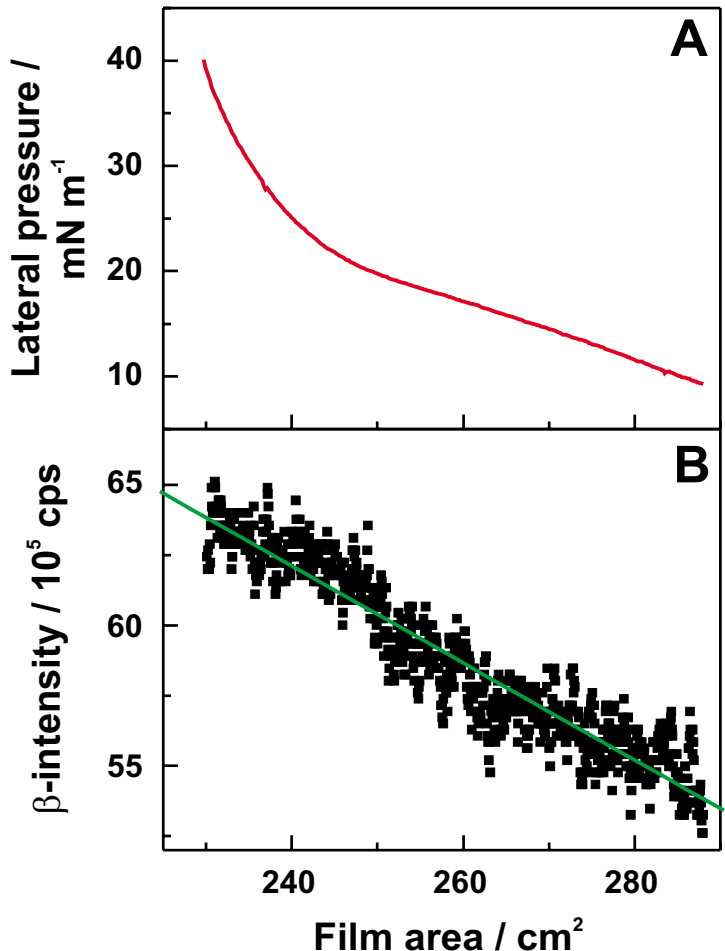

Figure 6

Dependence of the $\beta$-intensity on area and lateral pressure of LPS F5 I 5 monolayers. (A) Pressure/area isotherm of a LPS F5I5 monolayer. (B) Linear change of the $\beta$-intensity of ${ }^{45} \mathrm{Ca}^{2+}$ adsorbed on the monolayer determined under a constant area of the monolayer (green line: linear fit). Bathing solution: $12.5 \mu \mathrm{M}$ calcium doped with radioactive ${ }^{45} \mathrm{Ca}^{2+}$ resulting in a relative $\beta$-activity of $250 \mathrm{~Bq} / \mathrm{ml}$, buffered with $5 \mathrm{mM}$ HEPES, and adjusted to $\mathrm{pH} 7$.

Thus, the calcium displacement method is a helpful complementation to characterize the interaction between lipid monolayers and peptides/proteins, because it is now possible to differentiate between intercalation and accumulation of peptides.

\section{Conclusion}

The characterization of the electrical potential of lipid membranes and of electrostatically driven interactions between lipids and peptides/proteins are important aims for an understanding of the molecular interaction mechanisms. The adsorption of calcium ions to lipid monolayers can be determined by measuring the $\beta$-intensity of ${ }^{45} \mathrm{Ca}^{2+}$ which is linearly proportional to the calculated net negative charge of the respective phospholipids or LPSs. Thus, calcium ions seem to bind to all negatively charged groups of LPS, even to those which are located close to the LPS backbone. Larger probe molecules might not be able to reach these groups. The peptide/protein-induced dis-

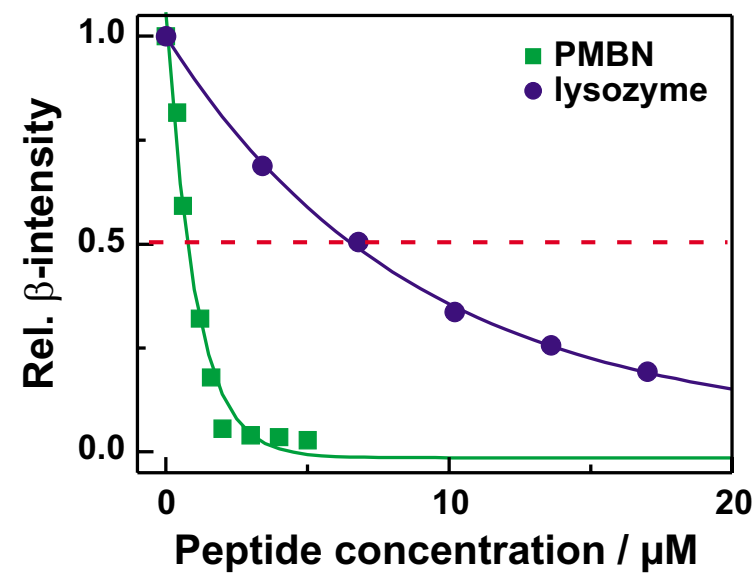

Figure 7

Displacement of calcium from LPS F5 I 5 monolayers by polymyxin B nonapeptide and lysozyme. Relative

change of the $\beta$-intensity in dependence on peptide/protein concentration after addition of the nonapeptide of polymyxin

B $(\square)$ or lysozyme $(O)$ into the subphase underneath LPSF5 I 5 monolayers. Bathing solution: $12.5 \mu \mathrm{M} \mathrm{Ca}^{2+}$ doped with radioactive ${ }^{45} \mathrm{Ca}^{2+}$ resulting in a relative $\beta$-activity of 250 $\mathrm{Bq} / \mathrm{ml}$, buffered with $5 \mathrm{mM}$ HEPES, and adjusted to $\mathrm{pH} 7$ and the LPS F5I 5 concentration was $9.6 \mathrm{nmol}$ (I60 nM).

placement of calcium ions is a usable parameter for the determination of the adsorption of molecules to lipid monolayers. The film balance experiments provide information on i) the adsorption of peptides at the monolayer surface caused by electrostatic interactions determined by calcium displacement and ii) the intercalation into the monolayer caused by electrostatic and hydrophobic interactions. In contrast to this, in calorimetric and surface plasmon resonance experiments it is difficult or in many cases not possible to distinguish between binding and intercalation.

The determination of the $\zeta$-potential provides valuable information for the characterization of the electrostatic interaction between peptides/proteins and phospholipid or LPS aggregates. However, due to the complexity of the LPS molecules, the theories, which are based on the assumption of flat surfaces, fail to describe the potential of LPS aggregates. The calculation of the respective planes of shear demonstrates that the $\zeta$-potentials depend on the number of saccharides and charged groups. As we showed earlier [43], the innermembrane potential difference, which can be determined from experiments using the inner-field compensation method [20] or the carrier transport by nonactin, also strongly depends on the thickness of the phospholipid or LPS headgroup regions. 


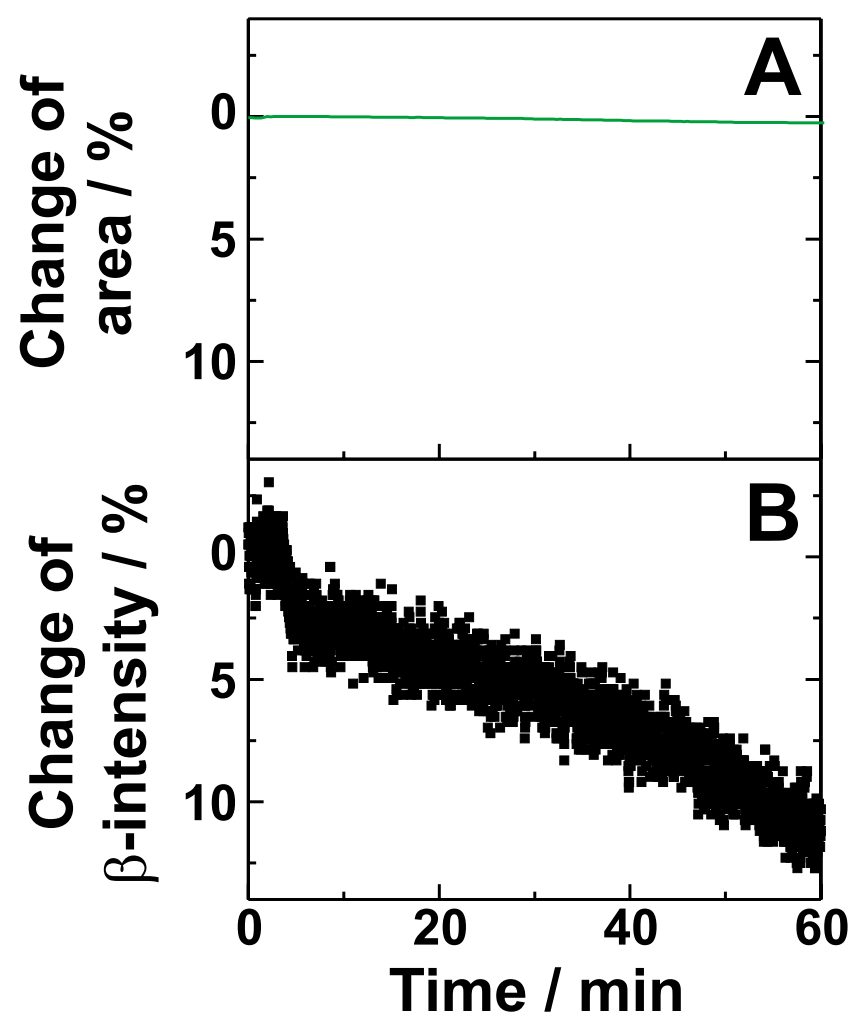

Figure 8

Influence of polymyxin B on the area of a monolayer and the adsorbed calcium. Injection of polymyxin B (350 $\mu \mathrm{M})$ underneath a LPS F5 I5 monolayer at a constant lateral pressure of $27 \mathrm{mN} \mathrm{m}^{-1}$ led to (A) no change of the area of the monolayer $(B)$ a decrease of the calcium adsorbed on the monolayer. Bathing solution: $12.5 \mu \mathrm{M} \mathrm{Ca}^{2+}$ doped with radioactive ${ }^{45} \mathrm{Ca}^{2+}$ resulting in a relative $\beta$-activity of $250 \mathrm{~Bq} / \mathrm{ml}$, buffered with $5 \mathrm{mM}$ HEPES, and adjusted to $\mathrm{pH} 7$.

It has been shown in many publications that the intercalation of peptides/proteins into lipid monolayers and bilayers can be different. However, according to Schoch et al. $[21,44]$ the electrostatic potential of the leaflet of the bilayer presented to the buffer is the same as that of the respective monolayer. Therefore, the peptide/proteininduced displacement of calcium ions from various monolayers and reduction of the $\zeta$-potential of aggregates are both based on the same electrostatic properties of the lipid matrices.

In summary, measurements of calcium adsorption and displacement provide additional useful information for the characterization of the electrostatic interaction between negatively charged monolayers and peptides/ proteins.

\section{Methods \\ Lipids and peptides/proteins}

Rough mutant LPS from Salmonella enterica serovar Minnesota (S. minnesota) strains R595 (LPS R595), R4 (LPS R4), R7 (LPS R7), Rz (LPS Rz), R5 (LPS R5), R345 (LPS $\mathrm{R} 345$ ), and R60 (LPS R60) as well as deep rough mutant LPS from Escherichia coli strain F515 (LPS F515) and Proteus mirabilis strain R45 (LPS R45) were used [45-50]. LPS was extracted by the phenol/chloroform/petroleum ether method [51], purified, lyophylized, and transformed into the triethylamine salt form. The chemical structures are given in Fig. 1. The amounts of nonstoichiometric substitutions by fatty acids (data not shown), Ara4N, additional phosphates, and phosphoethanolamine were analyzed by mass spectrometry. In LPS R595, the Ara4N linked to the 4 '-phosphate was present at a level of $40 \%$. In LPS R45, approximately $50 \%$ of the 4 '-phosphate of lipid A and $50 \%$ of the first Kdo were substituted with Ara4N. By taking into account the amounts of negatively charged phosphate groups and Kdo's and the positively charged Ara4Ns the net charges of the LPSs as summarized in Tab. 1, were calculated.

Phosphatidylcholine (PC) from egg yolk lecithin, phosphatidylglycerol (PG) from egg yolk lecithin (sodium salt), and synthetic diphosphatidylglycerol (DPG) were purchased from Avanti Polar Lipids (Alabaster, AL, USA) and used without further purification.

Polymyxin B (PMB) and its nonapeptide (PMBN), lactoferrin from human milk, lactalbumin from bovine milk, lysozyme from chicken egg white, and human hemoglobin were purchased from Sigma Aldrich (Deisenhofen, Germany), and recombinant human serum albumine (rHSA) from Welfide Corporation (Osaka, Japan). Recombinant $\mathrm{BPI}_{1-193}$ (rBPI21) was a kind gift of XOMA (Berkeley, CA, USA). The rabbit CAP18 $8_{106-137}$ was a kind gift provided by J.W. Larrick (Palo Alto Institute of Molecular Medicine, Mountain View, CA, USA).

\section{Determination of the surface potential}

Fixed charges within the headgroups of lipid molecules cause an electric potential at the lipid bilayer surface with respect to the surrounding bathing solution, the surface potential $[27,52]$. The $\zeta$-potential is related to the surface potential of the lipid aggregates, and can be calculated from the electrophoretic mobility of the aggregates according to the Smoluchowski approximation [53]:

(Eq. 4) $\zeta=\mu \eta /\left(\varepsilon_{\mathrm{r}} \varepsilon_{0}\right)$

where $\zeta$ is the $\zeta$-Potential, $\mu$ the electrophoretic mobility, $\eta$ the viscosity $\left(0.89 \cdot 10^{-3} \mathrm{~kg} \mathrm{~m}^{-1} \mathrm{~s}^{-1}\right), \varepsilon_{0}$ the dielectric constant of vacuum $\left(8.854 \cdot 10^{-12} \mathrm{~A}^{2} \mathrm{~s}^{4} \mathrm{~kg}^{-1} \mathrm{~m}^{-3}\right)$ and $\varepsilon_{\mathrm{r}}$ the dielectric permittivity of water (78.54). 
To study the surface potential of phospholipid and LPS aggregates, we determined their $\zeta$-potentials. The measurements were performed on a ZetaSizer4 (Malvern Instruments $\mathrm{GmbH}$, Herrsching, Germany) at $25^{\circ} \mathrm{C}$ and with a driving electric field of $19.2 \mathrm{~V} \mathrm{~cm}^{-1}$.

Aggregates were prepared as $1 \mathrm{mM}$ aqueous dispersions of lipid in buffer ( $10 \mathrm{mM}$ Tris, $\left.2 \mathrm{mM} \mathrm{CsCl}{ }_{2}, \mathrm{pH} 7\right)$. Briefly, the lipid dispersions were sonicated for $20 \mathrm{~min}$ at $60^{\circ} \mathrm{C}$, cooled down to $4^{\circ} \mathrm{C}$ for $30 \mathrm{~min}$ and temperature-cycled twice between $60^{\circ} \mathrm{C}$ and $4^{\circ} \mathrm{C}$ (30 min each). The dispersions were equilibrated overnight at $4{ }^{\circ} \mathrm{C}$. Prior to $\zeta$ potential measurements, lipid dispersions were diluted to a final concentration of $0.01 \mathrm{mM}$. Presented values (Fig. 3 ) are mean values with standard derivations resulting from 3 to 5 independent experiments.

\section{Preparation of lipid monolayers used in film balance experiments}

In general, two types of Langmuir-Pockels film balance experiments were utilized: (i) at a constant and (ii) at a variable film area. In both types of experiments the phospholipids were dissolved in chloroform and the LPSs in a 10:1 (v:v) mixture of chloroform and methanol at a concentration of $1 \mathrm{mM}$. All lipids were deposited in the given amounts on the subphase and the solvents were allowed to evaporate for $5 \mathrm{~min}$.

\section{Determination of calcium adsorption to and displacement from lipid monolayers}

Calcium adsorption to lipid monolayers prepared from phospholipids or LPSs was determined by depositing 10 nmol of the respective lipid on $60 \mathrm{ml}$ of an aqueous subphase buffered with $5 \mathrm{mM}$ HEPES and adjusted to pH7. After equilibration of the monolayer, 5 aliquots of $200 \mu \mathrm{l}$ of a $1.5 \mathrm{mM}$ calcium solution adjusted to a relative $\beta$ activity of $24 \mathrm{kBq} / \mathrm{ml}$ with radioactive ${ }^{45} \mathrm{Ca}^{2+}$ (Amersham Buchler, Braunschweig, Germany) were added to the subphase, resulting in a final calcium concentration of $25 \mu \mathrm{M}$. Calcium ions bind to the negatively charged headgroups of the lipids, and the low-energy $\beta$-radiation originating from the bound ${ }^{45} \mathrm{Ca}^{2+}$ is not absorbed by the hydration shell anymore and, therefore, an increase in $\beta$-intensity was observed using a $\beta$-counter (gas ionization detector LB124, Berthold, Wildbad, Germany) (Fig 2, step 1 \& 2). Thus, this method allows the determination of the relative amount of calcium bound to the monolayer [24]. To keep the number of lipid molecules and, therefore, the potential number of binding sites for calcium underneath the detection area of the $\beta$-counter constant, the experiments were performed in an acrylic glass trough with a total constant film area of $112 \mathrm{~cm}^{2}$.
The $\beta$-intensity $I_{\text {mono }}$ originating from ${ }^{45} \mathrm{Ca}^{2+}$ bound to the lipid monolayer at a given $\mathrm{Ca}^{2+}$ concentration was calculated according to the equation:

(Eq. 5) $I_{m o n o}=I_{t o t}-I_{s u b}$

where $I_{\text {tot }}$ is the $\beta$-intensity originating from the monolayer and the subphase and $I_{\text {sub }}$ is the $\beta$-intensity of the pure subphase. These and the following experiments were performed at a subphase temperature of $20^{\circ} \mathrm{C}$ instead of $37^{\circ} \mathrm{C}$ to avoid condensation at the $\beta$-counter.

To investigate the capacity of various peptides/proteins to displace divalent $\mathrm{Ca}^{2+}$ ions from LPS F515 monolayers, a subphase containing $12.5 \mu \mathrm{M} \mathrm{Ca}^{2+}$ doped with radioactive ${ }^{45} \mathrm{Ca}^{2+}$ (resulting in a relative $\beta$-activity of $250 \mathrm{~Bq} / \mathrm{ml}$ ), buffered with $5 \mathrm{mM}$ HEPES at $\mathrm{pH} 7$ was used. Also in the displacement experiments, the number of LPS molecules was kept constant. The agents were added to the subphase at a constant total film area and relatively low lateral pressure of the monolayer $\left(\sim 10 \mathrm{mN} \mathrm{m}^{-1}\right)$. This way, the final pressure after saturation of the intercalation of agents was still in the range of lateral pressures in biological membranes $[41,42]$. The peptides/proteins were added to the subphase in different concentrations, and the equilibrium $\beta$-counting rates were recorded (Fig. 2, step 3). The relative $I_{r e l}(c)$ in dependence on the peptide/protein concentration $c$ was calculated from

(Eq. 6) $I_{\text {rel }}(c)=\frac{I_{t o t}(c)-I_{s u b}}{I_{\text {mono }}}$

where $I_{t o t}(c)$ is the absolute $\beta$-intensity, $I_{\text {sub }}$ the $\beta$-intensity originating from the pure subphase, and $I_{\text {mono }}$ the $\beta$-intensity originating from the monolayer. From the displacement curves the concentrations at which $50 \%$ of the calcium were displaced ( $\mathrm{IC}_{50}$ value) by the peptides/proteins were determined and summarized in Tab. 1.

All presented values are mean values with standard derivations resulting from 3 to 4 independent experiments.

\section{Influence of the lateral pressure on the adsorption of calcium to LPS monolayers}

A Langmuir-Pockels film balance equipped with a Wilhelmy system (Munitech, München, Germany) was used to determine the lipid pressure/area isotherms of LPS F515 monolayers. The lateral pressure, area, and the $\beta$ intensity were determined. For the experiments, $36 \mu \mathrm{l}$ of the LPS F515 were spread on the buffer surfaces of 290 $\mathrm{cm}^{2}$. The solvent was allowed to evaporate at zero pressure for $5 \mathrm{~min}$. Then the monolayers were isothermally compressed at a speed of $1.5 \mathrm{~mm}^{2} \mathrm{~s}^{-1}$ to a lateral pressure of 40 $\mathrm{mN} \mathrm{m}^{-1}$. 


\author{
Abbreviations \\ AMP - antimicrobial peptides \\ Ara4N - 4-amino-4-deoxyarabinose \\ BPI - bactericidal/permeability increasing protein \\ DPG - diphosphatidylglycerol \\ ENP - endotoxin-neutralizing protein \\ Kdo - 3-deoxy-alpha-D-manno-oct-2-ulosonic acid \\ LPS - lipopolysaccharide \\ LTA - lipoteichoic acid \\ OM - outer membrane \\ PC - phosphatidylcholine \\ PE - phosphatidylethanolamine \\ PEG - poly(ethylene glycol) \\ PG - phosphatidylglycerol \\ $\mathrm{PMB}$ - polymyxin B \\ PMBN - nonapeptide of PMB \\ PS - phosphatidylserine \\ rBPI21 - recombinant $21 \mathrm{kDa}$ fragment of BPI \\ rCAP18 - 18 kDa rabbit cationic antimicrobial protein \\ rHSA - recombinant human serum albumin
}

\section{Authors' contributions}

$\mathrm{SOH}$ designed and carried out the adsorption binding assay and drafted the manuscript. MUH carried out the $\zeta$ potential experiments and helped to draft the manuscript. AW participated in the film balance experiments. US participated in the design of the study and helped to draft the manuscript. TG participated in the design and coordination of the study, performed some of the monolayer experiments and helped to draft the manuscript. All authors read and approved the final manuscript.

\section{Acknowledgements}

This work was financially supported by the Deutsche Forschungsgemeinschaft (SFB 470, project B5).

The authors are indebted to Dr. Buko Lindner, Helga Lüthje, and Brigitte Kunz from the Research Center Borstel for preparation and mass spectro- metric analysis of the LPSs utilized in this study. We would also like to thank Yvonne Eckstein, Petros Papastogiannidis, and Witali Gering for technical assistance.

\section{References}

I. Boon JM, Smith BD: Chemical control of phospholipid distribution across bilayer membranes. Med Res Rev 2002, 22:25I-28I.

2. Hanshaw RG, Lakshmi C, Lambert TN, Johnson JR, Smith BD: Fluorescent Detection of Apoptotic Cells by Using Zinc Coordination Complexes with a Selective Affinity for Membrane Surfaces Enriched with Phosphatidylserine. Chembiochem 2005, 6:2214-2220.

3. Schröder-Borm H, Bakalova R, Andrä J: The NK-lysin derived peptide NK-2 preferentially kills cancer cells with increased surface levels of negatively charged phosphatidylserine. FEBS Lett 2005, 579:6|28-6|34.

4. Paton JC, May BK, Elliott WH: Membrane phospholipid asymmetry in Bacillus amyloliquefaciens. J Bacteriol 1978, I35:393-40I.

5. Sutcliffe IC, Russell RR: Lipoproteins of gram-positive bacteria. J Bacteriol 1995, 177: I 123-II28.

6. Nikaido H, Vaara M: Outer membrane. In Escherichia coli and Salmonella typhimurium. Cellular and Molecular Biology Edited by: Neidhardt C, Ingraham JL, Brooks Low K, Magasnaik B, Schaechter M, Umbarger HE. Washington, DC: American Society for Microbiology; 1987:7-22.

7. Kagan BL, Ganz T, Lehrer RI: Defensins: a family of antimicrobial and cytotoxic peptides. Toxicology 1994, 87: I 31 - I 49.

8. Gutsmann T, Hagge SO, Larrick JW, Seydel U, Wiese A: Interaction of CAPI8-Derived Peptides with Membranes Made from Endotoxins or Phospholipids. Biophys J 200I, 80:2935-2945.

9. Wiese A, Brandenburg K, Lindner B, Schromm AB, Carroll SF, Rietschel ET, Seydel U: Mechanisms of action of the bactericidal/ permeability-increasing protein BPI on endotoxin and phospholipid monolayers and aggregates. Biochemistry 1997, 36: $10301-10310$.

10. Dathe M, Nikolenko H, Meyer J, Beyermann M, Bienert M: Optimization of the antimicrobial activity of magainin peptides by modification of charge. FEBS Lett 200I, 50 I:I46-I50.

II. Fletcher MA, McKenna TM, Quance JL, Wainwright NR, Williams TJ: Lipopolysaccharide detoxification by endotoxin neutralizing protein. J Surg Res 1993, 55:|47-I54.

12. Gough M, Hancock REW, Kelly NM: Antiendotoxin activity of cationic peptide antimicrobial agents. Infect Immun 1996, 64:4922-4927.

13. Ohno N, Takada K, Kurasawa T, Liang AH, Yadomae T: Detoxification of lipopolysaccharide by lysozyme. Prog Clin Biol Res 1998, 397:179-190.

14. Andrä J, Lamata M, Martinez dT, Bartels R, Koch MH, Brandenburg K: Cyclic antimicrobial peptides based on Limulus anti-lipopolysaccharide factor for neutralization of lipopolysaccharide. Biochem Pharmacol 2004, 68: I 297- 1307.

15. Gutsmann T, Muller M, Carroll SF, MacKenzie RC, Wiese A, Seydel $U$ : Dual role of lipopolysaccharide (LPS)-binding protein in neutralization of LPS and enhancement of LPS-induced activation of mononuclear cells. Infect Immun 200 I, 69:6942-6950.

16. Alexander C, Rietschel ET: Bacterial lipopolysaccharides and innate immunity. J Endotoxin Res 2001, 7:167-202.

17. Wilson WW, Wade MM, Holman SC, Champlin FR: Status of methods for assessing bacterial cell surface charge properties based on zeta potential measurements. J Microbiol Methods 200I, 43:153-164.

18. Pickard WF, Sehgal KC, Jackson CM: Measurement of phospholipid monolayer surface potentials at a hydrocarbon-electrolyte interface. Biochim Biophys Acta 1979, 552:I-10.

19. Vogel V, Möbius D: Local surface potentials and dipole moments of lipid monolayers: contributions of the water/ lipid and lipid/air interfaces. J coll Interf Sci 1988, I 26:408-420.

20. Sokolov VS, Kuz'min VG: Study of surface potential difference in bilayer membranes according to the second harmonic response of capacitance current. Biofizika 1980, 25:170-172.

21. Schoch P, Sargent DF, Schwyzer R: Capacitance and conductance as tools for the measurement of asymmetric surface potentials and energy barriers of lipid bilayer membranes. J Membr Biol 1979, 46:71-89. 
22. Hauser $\mathrm{H}$, Dawson RM: The binding of calcium at lipid-water interfaces. Eur J Biochem 1967, I:61-69.

23. Vogelgesang R, Wood G, Peters T, Scheufler E: pH-dependent influence of membrane-incorporated flunarizine on Ca-binding to phosphatidylserine monolayer membranes. Biochem Pharmacol 1988, 37:1597-1600.

24. Lüllmann $\mathrm{H}$, Plösch $\mathrm{H}$, Ziegler $\mathrm{A}$ : Ca replacement by cationic amphiphilic drugs from lipid monolayers. Biochem Pharmacol 1980, 29:2969-2974.

25. Klein CD, Tabeteh GF, Laguna AV, Holzgrabe U, Mohr K. Lipophilicity and membrane interactions of cationicamphiphilic compounds: syntheses and structure-property relationships. EurJ Pharm Sci 200I, I4:167-I75.

26. Hagge SO, Wiese A, Seydel U, Gutsmann T: Inner field compensation as a tool for the characterization of asymmetric membranes and Peptide-membrane interactions. Biophys J 2004, 86:913-922.

27. Cevc G: Membrane electrostatics. Biochim Biophys Acta 1990 | $031: 3 \mid$ | -382.

28. von Smoluchowski M: Versuch einer mathematischen Theorie der Koagulationskinetik kolloider Lösungen. Z Phys Chem 1917, 92:129-168.

29. Snyder S, Kim D, Mclntosh T]: Lipopolysaccharide bilayer structure: effect of chemotype, core mutations, divalent cations, and temperature. Biochemistry 1999, 38:10758-10767.

30. Brandenburg K: Fourier transform infrared spectroscopy char acterization of the lamellar and nonlamellar structures of free lipid A and Re lipopolysaccharides from Salmonella minnesota and Escherichia coli. Biophys J 1993, 64:1215-1231.

31. Pasquale L, Winiski A, Oliva C, Vaio G, McLaughlin S: An experimental test of new theoretical models for the electrokinetic properties of biological membranes. The effect of UO2++ and tetracaine on the electrophoretic mobility of bilayer membranes and human erythrocytes. I Gen Physiol 1986, 88:697-7I8

32. McDaniel RV, Sharp K, Brooks D, McLaughlin AC, Winiski AP, Cafiso $D$, McLaughlin S: Electrokinetic and electrostatic properties of bilayers containing gangliosides GMI, GDIa, or GTI. Comparison with a nonlinear theory. Biophys J 1986, 49:74I-752.

33. Woodle MC, Collins LR, Sponsler E, Kossovsky N, Papahadjopoulos D, Martin FJ: Sterically stabilized liposomes. Reduction in electrophoretic mobility but not electrostatic surface potential. Biophys J 1992, 61:902-910.

34. Roes S, Seydel U, Gutsmann T: Probing the properties of lipopolysaccharide monolayers and their interaction with the antimicrobial peptide polymyxin B by atomic force microscopy. Langmuir 2005, 21:6970-6978.

35. Ohshima H: Electrophoresis of Soft Particles. Adv Colloid Interface Sci 1995, 62:189-235.

36. Gutsmann T, Hagge SO, Larrick JW, Seydel U, Wiese A: Interaction of CAPI8-derived peptides with membranes made from endotoxins or phospholipids. Biophys J 200I, 80:2935-2945.

37. Brandenburg K, Jürgens G, Muller M, Fukuoka S, Koch MH: Biophysical characterization of lipopolysaccharide and lipid $A$ inactivation by lactoferrin. Biol Chem 200I, 382:12 I5-1225.

38. Jürgens $G$, Müller $M$, Garidel $P$, Koch $M H$, Nakakubo $H$, Blume $A$ Brandenburg $\mathrm{K}$ : Investigation into the interaction of recombinant human serum albumin with Re-lipopolysaccharide and lipid A. J Endotoxin Res 2002, 8: I I5- 26.

39. Jürgens G, Müller M, Koch MH, Brandenburg K: Interaction of hemoglobin with enterobacterial lipopolysaccharide and lipid A. Physicochemical characterization and biological activity. Eur J Biochem 200I, 268:4233-4242.

40. Nikaido H, Vaara M: Molecular basis of bacterial outer membrane permeability. Microbial Rev 1985, 49:I-32.

41. Marcelja S: Chain ordering in liquid crystals II. Structure of bilayer membranes. Biochim Biophys Acta 1974, 367:165-176.

42. Blume A: A comparative study of the phase transition of phospholipid bilayers and monolayers. Biochim Biophys Acta 1979, 557:32-44.

43. Hagge SO, Wiese A, Seydel U, Gutsmann T: Inner field compensation as a tool for the characterization of asymmetric membranes and peptide-membrane interactions. Biophys J 2004, 86:913-922.

44. Schoch P, Sargent DF: Surface potentials of asymmetric lipid bilayers. Experientia 1976, 32:8II.
45. Zähringer U, Lindner B, Seydel U, Rietschel ET, Naoki H, Unger FM, Imoto M, Kusumoto S, Shiba T: Structure of de-O-acylated lipopolysaccharide from the Escherichia coli Re mutant strain F 515. Tetrahedron Letters 1985, 26:632I-6324.

46. Rietschel ET, Brade L, Lindner B, Zähringer U: Biochemistry of lipopolysaccharides. In Bacterial Endotoxic Lipopolysaccharides, Molecular Biochemistry and Cellular Biology Volume I. Ist edition. Edited by: Morrison DC, Ryan JL. Boca Raton: CRC Press; 1992:3-4I.

47. Rietschel ET, Kirikae T, Schade FU, Mamat U, Schmidt G, Loppnow H, Ulmer AJ, Zähringer U, Seydel U, Di Padova F, et al.: Bacterial endotoxin: molecular relationships of structure to activity and function. FASEB $\int$ | $994,8: 217-225$

48. Vinogradov EV, Thomas-Oates JE, Brade H, Holst O: Structural investigation of the lipopolysaccharide from Proteus mirabilis R45 (Re-chemotype). Journal of Endtotoxin Research 1994, I:199-206.

49. Wiese A, Münstermann M, Gutsmann T, Lindner B, Kawahara K, Zähringer U, Seydel U: Molecular mechanisms of Polymyxin Bmembrane interactions: direct correlation between surface charge density and self-promoted uptake. J Membr Biol 1998, 162:127-138.

50. Holst O: Chemical structure of the core region of lipopolysaccharides. In Endotoxin in Health and Disease Ist edition. Edited by: Brade H, Opal SM, Vogel SN, Morrison DC. New York: Marcel Dekker, Inc; 1999:II5-I54.

5I. Galanos C, Lüderitz O, Westphal O: A new method for the extraction of $\mathbf{R}$ lipopolysaccharides. Eur J Biochem 1969, 9:245-249.

52. Cevc G: Electrostatic characterization of liposomes. Chem Phys Lipids 1993, 64:163-186.

53. Hunter RJ: Zeta potential in colloid science London: Academic Press; 1981.
Publish with Bio Med Central and every scientist can read your work free of charge

"BioMed Central will be the most significant development for disseminating the results of biomedical research in our lifetime. "

Sir Paul Nurse, Cancer Research UK

Your research papers will be:

- available free of charge to the entire biomedical community

- peer reviewed and published immediately upon acceptance

- cited in PubMed and archived on PubMed Central

- yours - you keep the copyright
BiolMedcentral 